last edition of a text.book or compendium and tracing the steps by which our present knowledge has been reached.

With regard, for instance, to the physiology of the circulation, it is not only curious but instructive to follow its gradual growth from Galen and Vesalius, Columbus, Cæsalpinus, and Servetus, to Harvey and Lower and Malpighi, to Hales and Vierordt, to Ludwig, and Chauveau, and Gaskell, and Roy. The only true scientific method is the historical one. If we only know the results of a science without the steps by which they have been reached, we have indeed its practical use, but lose half its educational value. We are almost in the position of an engineer who knows the conclusions of trigonometry by rote, but is ignorant of the demonstration. I would therefore urge upon junior Fellows, while still enjoying the prospect rather than the fruition of professional success, to spare some of the time which is unoccupied by work in wards and laboratories for the perusal of such antiquated works as have been published as much as twenty years ago, and particularly for gaining acquaintance at first hand with classics like Virchow's "Cellular Pathology," and the lectures of Watson, Trousseau, and Stokes; or, if their time and inclination does not allow of more extended researches, at least to read such succinct masterpieces as Laennec's "Mediate Auscultation," Heberden's "Commentaries," Sydenham's "Treatise on Gout," and Harvey, "On the Movement of the Heart and of the Blood."

(3) I would, moreover, exhort Fellows of the College to see that, while all the new methods of experimental pathology and pharmacology are carried out by duly trained physiologists, we do not neglect the fundamental method taught and practised by Harvey of inspecting the bodies of those who have died of disease. It was this union of morbid anatomy with clinical observation which made the discoveries of Laennec and of Bright really fruitful. Without these autopsies, clinical medicine is but an empirical art, diagnosis a sham, and treatment little better than quackery. Exclusive attention to therapeutics is apt to bring a man dangerously near to homceopathy and other pretended systems of treatment, but sound pathology, and diagnosis controlled by post-mortem inspection, give positive knowledge and that union of modest self-confidence and prudent enterprise which become the physician.

Lastly, I have to fulfil the duty of exhorting the Fellows of this ancient College "to continue in mutual love and affection" among ourselves; and this is the easiest task of all. For, if we must admit that experimental science in England, and particularly scientific pathology, is not surpassing our byegone achievements as it ought to surpass them, considering the increased number of competent labourers and the vastly improved methods of research ; and if we admit that the crowd of modern literature, and the distractions which we fondly imagine to be peculiar to our generation, leave small opportunity for the cultivation of ancient learning; and if the prejudices of our patients, both gentle and simple, still make post-mortem inspections less common and systematic than they should bewhatever, I say, may be our shortcomings in these or in other respects-your Harveian orator may most honestly congratulate the College and the profession upon the concord and mutual esteem which has happily marked our history from the days of Linacre to those of Harvey, from the days of Arbuthnot and Garth to those of Meade and Freind, from the days of Fothergill and Heberden to those of Matthew Baillie, of Babington, and of Sir Thomas Watson. Long may this continue, for thereon depend not only the dignity and peace of our profession, but in great measure our power of doing good. However ignorantly our patients will sometimes decry what they call professional etiquette, the wiser among them know (and in the long run the wise lead the foolish) that this term really means the observance of the rules which distinguish a profession from a trade, which make our calling honourable as well as honest, which check the arts of advertisement and direct our ambition to obtaining the suffrages, not of the public which cannot, but of our profession which can, judge truly-rules of conduct which are, in fact, nothing but the carrying into daily practice of the golden rule to do to others as we wnuld they should do to us. For maintaining and strengthening this spirit of concord and good feeling, we depend upon each one of our Fellows, but especially on the example and authority of our Head-an example and authority which, as the College well knows, are worthily maintained by the untiring devotion to its best interests of our honoured President.

\section{THE EFFECT OF WATER VAPOUR ON} ELECTRICAL DISCHARGES.

A VERY interesting paper by Prof. J. J. Thomson, on the effects of electrification and chenical action on a steam jet, and of water vapour on the discharge of electricity through gases, appears in the October number of the Philo. sophical Magazine. In it the author first considers the effect of an electrical field on the surface tension of a water drop, and he shows that if the electrical field is uniform, the diminution in the surface tension is very small and independent of the size of the drop ; so that a uniform field will not be able to counterbalance the effect of surface tension, since the latter varies inversely as the radius of the drop, and therefore when the drop is excessively small must be greater than the constant effect due to the electric field. When, however, the electric field instead of being uniform is due to a number of charged atoms distri. buted throughout the volume occupied by the steam, the effect of the electric field in diminishing the surface tension varies inversely as the square of the radius of the drop. Thus for very small drops the electrification will overpower the cause (surface tension) which, under ordinary circumstances, puts an end to the existence of small drops. The above seems capable of explaining the effects of electrification on a steam jet first observed by Helmholtz, for the electricity which escapes into the gas is carried by charged atoms of the gas, and since in the region immediately around these atoms there will be a very intense electric field there will be a tendency for the steam to condense into drops in these regions. Helmholtz also discovered that chemical action in the neighbourhood of the jet affected it in much the same way as a discharge of electricity. If the forces which hold the atoms together in a molecule are electrical in their origin, so that in a diatomic molecule one atom has a positive and the other an equal negative charge, the above explanation will also apply to this case. For when the molecule of the gas is in the ordinary state, the equal and opposite charges of the atoms will, in the region outside the molecule, neutralise each other's effect, so that the electrical field round a molecule will be much less intense than that round a single charged atom, and thus, though the field round the latter may be sufficient to cause condensation, that round the molecule may not. When, however, the molecules which enter into chemical combination come together and form a new compound, requiring a rearrangement of the atoms, then while the chemical change is going on, there will be an interval during which the atoms are comparatively free, and there will be an electric field almost as strong as if the atom were dissociated.

The author also considers the effect of moisture in promoting chemical action, for if the forces which hold the atoms in the molecule together are electrical in their origin it is evident that these forces will be very much diminished when the molecule is near the surface of, or surrounded by, a conductor or a sub. stance like water having a high specific inductive capacity. Thus if $A$ and $B$ represent two atoms in a molecule placed near a conducting sphere, then the effect of the electricity induced on the sphere by A will be represented by an opposite charge placed at the image of $\mathrm{A}$ in the sphere. If $\mathrm{A}$ is very near the sphere, this opposite charge will be very nearly equal to that at $\mathrm{A}$. Thus the effect of the sphere will be to practically neutralise the electrical effects of $\mathbf{A}$, and as one of these effects is to hold the atom $B$ in combination, the affinity between the atoms $A$ and $B$ will be almost entirely annulled by the presence of the sphere. Molecules condensed on the surface of a drop of water or surrounded by water will thus be practically dissociated, or at any rate the forces between their component atoms will be much reduced. Since water vapour produces so great an effect on chemical combination, it is interesting to investigate whether its presence has any considerable influence on the passage of electricity through gases, since there is strong evidence that this phenomenon is closely connected with chemical changes taking place in the gas through which the discharge takes place. Observations were made on dry and damp hydrogen, and show that there is a marked difference both in the appearance of the spark and in the proportion between the potential difference necessary to produce the first spark through the gas, and that which is sufficient to cause one to follow it immediately afterwards. In the damp gas this difference was comparatively small, averaging about ten per cent. In the dry gas, however, this effect attains quite abnormal proportions, the potential difference required to produce the first spark being often more

$$
\text { No. I } 25 \text { I, voL. } 48 \text { ] }
$$


than twice that required to maintain it when once started. These experiments show that the behaviour of a gas with reference to the passage of an electric spark is analogous to that of a vapour condensing to a liquid, the freezing of a liquid, or the deposition of crystals from a saturated solution. For in the case of a gas which contains a foreign substance (water vapour) the potential difference which the gas can support without a spark passing is approximately steady, but when the gas is carefully dried it can support an abnormally large potential difference, though when once the discharge has started the potential difference at once falls to its normal value. The passage of the spark producing a supply of moäified gas which persists for some time after the discharge has stopped.

\section{UNIVERSITY AND EDUCATIONAL INTELLIGENCE.}

OXFORD. - The opening of the new department of Human Anatomy was the occasion of some ceremony on Saturday afternoon. The Vice-Chancellor presided at a large gathering of scientific and medical men, including some distinguished visitors from the leading medical schools and universities. After speeches from Sir William Turner, Mr. Arthur Thomson, Sir Henry Acland, and Prof. MacAlister, the Vice-Chancellor declared the buildings open, and the proceedings closed with a vote of thanks to the Vice-Chancellor, moved by Prof. Burdon Sanderson

The lectures and practical courses in the Natural Science Department are as follows for the current term :- In Physics, Prof. Clifton lectures on Electricity, and gives practical instruction with the assistance of Mr. J. Walker and Mr. S. A. F. White. Mr. R. E. Baynes, lectures at Christ Church on Heat and Light, and Sir John Conroy and Mr. F. J. Smith lecture at Balliol and at Trinity College, respectively, on Elementary Physics and on Mechanics and Physics.

In Chemistry, Prof. Odling lectures on Organic Chemistry, and $\mathrm{Mr}$. W. W. Fisher, on Inorganic Chemistry. Other lectures and practical instruction are given by $\mathrm{Mr}$. J. Watts, Mr. V. H. Veley, Mr. J. E. Marsh, and Mr. J. A. Gardner. Mr. Vernon Harcourt and Mr. P. Elford lecture at Christ Church and St. John's respectively. Prof. A. H. Green lectures on Geology in the Museum on Mondays, Wednesdays, and Fridays.

Prof. Ray Lankester lectures three days a week on the Com. parative Anatomy of the Vertebrata, and Dr. W. B. Benham and Mr. G. C. Bourne give other lectures in the Linacre Professor's Department. Mr. J. Barclay Thompson lectures on the Osteology of Fish and Amphibia; and the Hope Professor of Zoology, on Means of Defence in the Struggle for Existence.

In Physiology, lectures and practical instruction in the subjects for the Final Honour Examination are given by Prof. Burdon Sanderson, Mr. J. S. Haldane, and Mr. M. S. Pembrey.

Prof. S. H. Vines gives advanced and elementary courses on Botany at the Botanical Gardens.

In Anthropology, lectures are announced by Dr. E. B. Tylor, by Mr. H. Balfour, and by Mr. Arthur Thomson.

It is announced that the examination for a Biological Fellowship at Merton College will commence on November I4.

Examinations for Natural Science Scholarships and Exhibitions at Balliol, Christ Church, and Trinity, are announced to begin on November $2 \mathrm{I}$.

CAMBRIDGE.-The Vice-Chanceilor gives notice that $\mathrm{Mr}$. H. Yule Oldham, University Lecturer in Geography, will deliver an inaugural lecture on the progress of geographical discovery, in the large lecture theatre of the chemical laboratory, on Tuesday, October 24 , at noon.

During the Michaelmas and Lent terms, Mr. Oldham will give courses of lectures on the principles of physical geography, in the same theatre, on Thursdays, at noon, beginning on October 26.

The Council of the Royal Geographical Society offer to award during the present academical year an exhibition of $£ 100$ to be spent in geographical investigation (physical or historical) of some district approved by the Council, to a member of the University of not more than eight years' standing, who shall have during his residence attended the courses of the lectures in geography. Further particulars will be announced.

The office of Director of the Fitzwilliam Museum is vacant by the resignation of Dr. Middleton. A new Director will be appointed on Friday, November 17. The stipend is 6.300 a year. Candidates are to send their names to the Vice-Chancellor by Friday, November 10.

The Walsingham Medal, founded by the High Steward of the University, will be offered during the present academical year for the best monograph or essay giving evidence of original research in any subject connected with biology or geology. Essays are to be sent to Prof. Newton by October 1, 1894 .

There are this year 132 freshmen who have indicated their in tention of studying medicine in the University.

Entrance Scholarships in Natural Science have been awarded at Christ's College to A.V. Cunnington $(£ 60)$, Clifton College, and J. Hart-Smith $(f 30)$, Berkhampstead School; and at Emmanuel College to W. F. A. Ermen $(£ 50)$, Clifton College, and R. G. K. Lempfert $(£ 50)$, Manchester Grammar School At Downing College an Examination for Minor Scholarships $(£ 50)$ in Natural Science will be held on April I7, 1894. At St. John's the Examination for Natural Science Scholarships ( $₫ 80$ and under) and Exhibitions ( $£ 50$ and under) will begin on December 5, 1893 .

THE United States Bureau of Education has published a remarkable "Circular of Information," by Dc. Arthur Macdonald, entitled "Abnormal Man." The volume includes essays on education and crime and related subjects, with digests of literature and an extensive bibliography. With regard to the effect of education on crime a statistical investigation shows that in France and Italy there has been an increase of both education and crime. Germany shows an increase of habitual criminality and a general increase of both university education and crime. As far as statistics are accessible, Austria shows an increase in education and a decrease in crime. Also, while there has been a decrease in the number of convictions for crime from $188 \mathrm{r}$ to $\mathrm{I} 887$ in Norway and Sweden, there has been an increase in education. But in Norway alone for the year $1888-89$ there was an increase in the number of crimes. In England, Scotland, and Ireland all statistics are in accord in showing an increase in education and a decrease in crime from 1885-1890. Japan and Saxony also exhibit an increase in education and a decrease in the number of convictions. It thus appears that while some countries show an increase in both education and crime, yet not a few, and some of the most developed nations, show an increase of education and a decrease of crime. The statistics, therefore, fail to show the exact relation between education and crime.

\section{SCIENTIFIC SERIALS.}

American Fournal of Mathematics, vol. xv. No. 3. (Baltimore, 1893).- On groups whose orders are products of three prime factors, by F. N. Cole and J. W. Glover (pp. I I-220) In this paper the authors fully determinel the groups for three prime factors, equal or unequal. Those of order $p q$ and $p^{2}$ are known from Netto. - The nature and effect of singularities of plane algebraic curves, by Miss Scott (pp. 22I-243) is a continuation of the paper in vol. xiv. In the earlier memoir the method employed was stated to be directly applicable, in general, to the determination only of the joint components of the singularity ; in this the restriction is removed, and it is shown that the process enables one, in every case, to enumerate the double lines (double tangents and inflexional tangents) involved in the singularity. -The elliptic irregularities in the lunar theory, by $\mathrm{E}$. W. Brown (pp. 244-263), gives a general solution in series of the problem : a system of three bodies is in motion in one plane, the first is revolving about the second, and is disturbed from its elliptic orbit by the third. The third body is supposed to be of infinite mass, and to be moving in a circle of infinite radius with a finite angular velocity. Given the relative positions of the three bodies at any one time, to find their relative positions at any other time. The differential equations used at the outset are given in Dr. Hill's paper (vol. i.) and M. Poincaré's researches (Acta Math. vol. xiii.) afford considerable help in the work. - On the transformation of linear differential equations of the second order with linear coefficient=, by Oskar Bolza (pp.

No. $125 \mathrm{I}$, VOL. 48 ] 